\title{
High Risk Sexual Behavior for HIV/AIDS and Migration Model among Ethnic Minority Migrants in China
}

\author{
Jian $\mathrm{Hu}^{1, \mathrm{a}}$ \\ ${ }^{1}$ Guizhou University of Finance and Economics, China \\ ajianhucdc@126.com
}

Keywords: Ethnic minority, Migrant, High risk sexual behavior for HIV/AIDS, Migration model.

\begin{abstract}
The Guizhou-Yunnan provincial border is the epidemic area of HIV/AIDS, and the HIV infection rate is high among ethnic minority migrants. This cross-sectional survey was conducted on the high risk sexual behavior for HIV/AIDS from July to October in 2012 in the factories, construction sites, and service establishments in Xingyi city, Qixingguan district, and Weining county, Guizhou province. 845 migrants with the experience of sexual intercourse were interviewed. The results show that the probability of the high risk sexual behavior for HIV/AIDS was higher among ethnic minority migrants (especially among ethnic Miao and Bouyi) than among ethnic Han migrants, and influenced by migration type, and number of floating city. The results suggest that the enterprise and government agency should improve the working condition and benefit of ethnic minority migrants to reduce the high risk sexual behavior for HIV/AIDS.
\end{abstract}

\section{Introduction}

A high risk sexual behavior for HIV/AIDS refers to a sexual behavior with a body fluid exchange between healthy individuals and people living with human immunodeficiency virus (HIV) or acquired immune deficiency syndrome (AIDS) patients. Migrant population is a target group of interventions on the high risk sexual behavior for HIV/AIDS [1]. Ethnic minority migrant population is a social vulnerable group and a bridge population of sexual transmission of HIV/AIDS because of the characteristics of mobility and low socio-economic status. However, few studies have reported on the high risk sexual behavior for HIV/AIDS among ethnic minority migrants in the remote western ethnic minority areas of P. R. China. There is no quantitative research on relationship between the high risk sexual behavior for HIV/AIDS and migration model $[2,3]$. The Guizhou-Yunnan provincial border is the epidemic area of HIV/AIDS in Guizhou province, and the HIV infection rate is high among ethnic minority migrants [4]. This cross-sectional survey was conducted on the high risk sexual behavior for HIV/AIDS among 845 migrants with the experience of sexual intercourses from July to October in 2012 in Xingyi city of Qianxinan autonomous prefecture of Buyi and Miao minorities, Qixingguan district and Weining autonomous county of Yi and Miao minorities of Bijie city, Guizhou province. The aims of this study were to describe the status of the high risk sexual behavior for HIV/AIDS, to analyze the effects of migration model on the high risk sexual behavior for HIV/AIDS among ethnic minority migrants on the Guizhou-Yunnan provincial border, and to provide scientific evidence for HIV/AIDS prevention policy-making.

\section{Methods}

\section{Study Population}

Migrant referred to male and female workers at the age of 15-60 years olds without household registration in the surveyed sub-district or town. The sample totaled 1270 respondents. Only 1037 respondents were eligible. The study population was 845 respondents who had the experience of sexual behavior (vaginal or anal or oral sexual intercourse).

\section{Study Area, Sampling and Measurement}

A multistage random sampling method was applied from July to October in 2012. Firstly, based on the mapping of ethnic minority migrants, this study selected Pingdong, Huangcao, Jushan, 
Xingtai sub-districts, Dingxiao and Weishe towns in Xingyi city, Xiaoba town in Qixingguan district, Caohai and Jinzhong towns in Weining county, where many ethnic minority migrants lived. Secondly, according to the occupational structure of ethnic minority migrants, the study selected randomly migrants in the ethnic minority working sites, e.g., factories, construction sites, service establishments (hotel, motel, sauna massage shop, restaurant, etc.). The project researchers and the graduate or undergraduate students were trained as investigators. The Guizhou Province Center for Disease Control and Prevention and the local department coordinated the survey. The one to one anonymous interview survey was conducted on the high risk sexual behavior for HIV/AIDS with a structured questionnaire. The questionnaire was designed based on the National Operation Manual of HIV/AIDS Sentinel Surveillance Program (2011) [5]. The survey included respondents' social economic characteristics, HIV/AIDS knowledge and attitudes, alcohol and drug information, prevention and control information of sexual transmitted disease and HIV/AIDS, and sexual behavior. The dependent variable was the high risk sexual behavior for HIV/AIDS, which referred to whether respondents had the commercial sexual behavior or casual sexual behavior or multiple partner sexual behavior in the last year or not. It was calculated based on the three questions in the questionnaire. For example, "Did you have a sexual intercourse with others to get money or some things in the last year?"; "Did you have a sexual intercourse with a temporary sexual partner (occasional and non-commercial sexual partner) in the last year?"; "Did you have a sexual intercourse with two or more sexual partners in the last year?". The high risk sexual behavior for HIV/AIDS was a binary variable. "Yes" was assigned in 1, "No" in 0. Migration model was measured by the three kinds of indexes.(1) Geographical indicator: Migration type referred to whether respondents crossed different provinces, counties (cities), townships (towns) in the last year or not; (2) Time indicator: Interval of going back home referred to the interval time (month) when respondents went back home in the last year. Time of leaving household registration referred to the time (month) when respondents left the hou sehold registration (sub-district or town) in the last year; (3) Floating frequency indicator: Number of floating city (town) referred to the number of city (town) where respondents left the household registration and went to other cities (towns ) for working in the last year.. Number of going home referred to the number of respondents' going back home in the last year. A binary variable was assigned in 1 and 0 . An ordinal variable was assigned in $1,2,3,4$, etc.

\section{Data Analysis}

$\chi^{2}$ test and multivariate logistic regression were performed with SPSS17.0.

\section{Results}

\section{Migration Model by Ethnic Group}

There were statistically significant differences in migration type and time of leaving household registration between ethnic minority migrant and ethnic Han migrant. See table 1.

Tab. 1 Migration Model by Ethnic Group (\%)

\begin{tabular}{|c|c|c|c|c|c|}
\hline Variable & $\begin{array}{c}\text { Ethnic minority } \\
(\mathrm{n}=247)\end{array}$ & $\begin{array}{c}\text { Ethnic Han } \\
(\mathrm{n}=598)\end{array}$ & $\begin{array}{c}\text { Total } \\
(\mathrm{n}=845)\end{array}$ & $\chi^{2}$ & $P$ \\
\hline Migration type & & & & 22.36 & 0.000 \\
\hline Crossing province & 4.9 & 14.5 & 11.7 & & \\
\hline Crossing county & 30.4 & 19.9 & 23.0 & & \\
\hline $\begin{array}{c}\text { Crossing town } \\
\text { Interval of going back home } \\
\text { (month) }\end{array}$ & 64.8 & 65.6 & 65.3 & & 0.312 \\
\hline$<1$ & 30.4 & 28.1 & 28.8 & & \\
\hline $1 \sim 2$ & 21.1 & 23.4 & 22.7 & & \\
\hline $3 \sim 5$ & 18.2 & 22.6 & 21.3 & & \\
\hline
\end{tabular}




\begin{tabular}{|c|c|c|c|c|c|}
\hline$\geqslant 6$ & 30.4 & 25.9 & 27.2 & & 0.002 \\
\hline $\begin{array}{c}\text { Time of leaving household } \\
\text { registration (month) }\end{array}$ & & & & 12.90 & \\
\hline$<6$ & 41.3 & 29.1 & 32.7 & & \\
\hline $6 \sim 12$ & 13.4 & 13.2 & 13.3 & & \\
\hline$>12$ & 45.3 & 57.7 & 54.1 & & 0.952 \\
\hline $\begin{array}{c}\text { Number of floating city } \\
\text { (town) }\end{array}$ & & & & & \\
\hline 1 & 54.3 & 55.7 & 55.3 & & \\
\hline 2 & 28.7 & 28.3 & 28.4 & & \\
\hline 3 & 9.3 & 8.2 & 8.5 & & \\
\hline$\geqslant 4$ & 7.7 & 7.9 & 7.8 & & \\
\hline $\begin{array}{c}\text { Number of going back } \\
\text { home }\end{array}$ & & & & 3.17 & \\
\hline 0 & 0.8 & 2.0 & 1.7 & & \\
\hline 1 & 17.4 & 18.7 & 18.3 & & \\
\hline 2 & 24.7 & 20.9 & 22.0 & & \\
\hline 3 & 42.5 & 44.8 & 44.1 & & \\
\hline 2 & 14.6 & 13.5 & 13.8 & & \\
\hline
\end{tabular}

\section{Association of High Risk Sexual Behavior for HIV/AIDS}

There was a significant difference in the high risk sexual behavior for HIV/AIDS among different ethnic group, gender, age, marital status, migration type, and number of floating city (town). See table

Tab. 2 Association of High Risk Sexual Behavior for HIV/AIDS

\begin{tabular}{|c|c|c|c|c|c|c|}
\hline \multirow{3}{*}{ Varible } & \multicolumn{4}{|c|}{ High risk sexual behavior for HIV/AIDS } & \multirow{3}{*}{$\chi^{2}$} & \multirow{3}{*}{$P$} \\
\hline & \multicolumn{2}{|c|}{ Yes } & \multicolumn{2}{|c|}{ No } & & \\
\hline & $\begin{array}{c}\mathrm{N} \\
(\mathrm{n}=463)\end{array}$ & $\begin{array}{l}\text { Percentage } \\
(\%)\end{array}$ & $\begin{array}{c}\mathrm{N} \\
(\mathrm{n}=382)\end{array}$ & $\begin{array}{c}\text { Percentage } \\
(\%)\end{array}$ & & \\
\hline Ethnic group & & & & & 20.32 & 0.000 \\
\hline Ethnic Han & 298 & 49.8 & 300 & 50.2 & & \\
\hline Ethnic minority & 165 & 66.8 & 82 & 33.2 & & \\
\hline Ethnic Miao & 55 & 79.7 & 14 & 20.3 & & \\
\hline Ethnic Bouyei & 66 & 66.7 & 33 & 33.3 & & \\
\hline Ethnic Dong & 11 & 57.9 & 8 & 42.1 & & \\
\hline Ethnic Yi & 19 & 55.9 & 15 & 44.1 & & \\
\hline Ethnic Hui etc. & 14 & 53.8 & 12 & 46.2 & & \\
\hline Gender & & & & & 22.85 & 0.000 \\
\hline Male & 327 & 61.0 & 209 & 39.0 & & \\
\hline Female & 136 & 44.0 & 173 & 56.0 & & \\
\hline Age & & & & & 10.80 & 0.004 \\
\hline $15 \sim 24$ & 106 & 59.2 & 73 & 40.8 & & \\
\hline $25 \sim 34$ & 248 & 57.9 & 180 & 42.1 & & \\
\hline$\geqslant 35$ & 109 & 45.8 & 129 & 54.2 & & \\
\hline Marital status & & & & & 6.32 & 0.012 \\
\hline Unmarried/divorced & 99 & 63.9 & 56 & 36.1 & & \\
\hline Married/cohabiting & 364 & 52.8 & 326 & 47.2 & & \\
\hline Migration type & & & & & 11.84 & 0.003 \\
\hline Crossing province & 39 & 39.4 & 60 & 60.6 & & \\
\hline Crossing county & 104 & 53.6 & 90 & 46.4 & & \\
\hline Crossing town & 320 & 58.0 & 232 & 42.0 & & \\
\hline $\begin{array}{l}\text { Number of floating city } \\
\text { (town) }\end{array}$ & & & & & 12.48 & 0.006 \\
\hline
\end{tabular}




\begin{tabular}{|c|r|r|r|r|r|l|}
\hline 1 & 240 & 51.4 & 227 & 48.6 & & \\
\hline 2 & 130 & 54.2 & 110 & 45.8 & & \\
\hline 3 & 52 & 72.2 & 20 & 27.8 & & \\
\hline$\geqslant 4$ & 41 & 62.1 & 25 & 37.9 & & \\
\hline
\end{tabular}

\section{Multivariate Logistic Regression on High Risk Sexual Behavior for HIV/AIDS}

Multivariate logistic regression analysis was performed with the high risk sexual behavior for HIV/AIDS as the dependent variable ( $\mathrm{Yes}=1, \mathrm{No}=0$ ), six variables as the independent variable, e.g., ethnic group, gender, age, marital status, migration type, and number of floating city (town). The results show that the model $\chi^{2}$ test had statistically significant $(\mathrm{P}<0.01)$. Ethnicity, gender, migration type, number of floating city (town) were positive predicting variables, which were the risk factors of the high risk sexual behavior for HIV/AIDS; Age was a negative predicting variable, which was the protecting factor of the high risk sexual behavior for HIV/AIDS. See table 3.

Tab. 3 Multivariate Logistic Regression on High Risk Sexual Behavior for HIV/AIDS

\begin{tabular}{|c|c|c|c|c|c|c|c|}
\hline Variable & Reference & $\beta$ & $S_{\bar{x}}$ & Wald $\chi^{2}$ & $P$ & OR & $95 \%$ CI \\
\hline Ethnic minority & Ethnic Han & & & 25.21 & 0.000 & & \\
\hline Ethnic Miao & & 1.36 & 0.32 & 18.02 & 0.000 & 3.88 & $2.08 \sim 7.26$ \\
\hline Ethnic Bouyei & & 0.73 & 0.24 & 9.43 & 0.002 & 2.08 & $1.30 \sim 3.32$ \\
\hline Ethnic Dong & & 0.35 & 0.49 & 0.52 & 0.473 & 1.42 & $0.54 \sim 3.74$ \\
\hline Ethnic Yi & & 0.28 & 0.37 & 0.55 & 0.458 & 1.32 & $0.63 \sim 2.75$ \\
\hline Ethnic Hui etc. & & 0.38 & 0.42 & 0.83 & 0.363 & 1.46 & $0.64 \sim 3.33$ \\
\hline Gender & Female & 0.86 & 0.16 & 30.24 & 0.000 & 2.37 & $1.74 \sim 3.22$ \\
\hline Age & $15-24$ & & & 12.08 & 0.002 & & \\
\hline $25-34$ & & -0.03 & 0.19 & 0.02 & 0.896 & 0.98 & $0.67 \sim 1.42$ \\
\hline$\geqslant 35$ & & -0.60 & 0.21 & 7.74 & 0.005 & 0.55 & $0.36 \sim 0.84$ \\
\hline $\begin{array}{c}\text { Migration type } \\
\text { Crossing }\end{array}$ & & & 12.13 & 0.002 & & \\
\hline Crossing county & province & 0.56 & 0.27 & 4.30 & 0.038 & 1.75 & $1.03 \sim 2.97$ \\
\hline Crossing town & & 0.82 & 0.24 & 11.55 & 0.001 & 2.27 & $1.41 \sim 3.63$ \\
\hline $\begin{array}{c}\text { Number of } \\
\text { floating city } \\
\text { (town) }\end{array}$ & 1 & & & 8.85 & 0.031 & & \\
\hline 2 & & & & & & & \\
\hline 3 & & 0.18 & 0.17 & 1.13 & 0.288 & 1.20 & $0.86 \sim 1.66$ \\
\hline$\geqslant 4$ & & 0.77 & 0.29 & 6.99 & 0.008 & 2.17 & $1.22 \sim 3.84$ \\
\hline Constant & & 0.48 & 0.29 & 2.78 & 0.096 & 1.62 & $0.92 \sim 2.85$ \\
\hline
\end{tabular}

Note: $-2 \log$ likelihood=1071.18; Model $\chi^{2}=92.46, \mathrm{P}=0.000$; Cox-Snell $\mathrm{R}^{2}=0.10$.

\section{Discussion}

The results show that the proportion of the high risk sexual behavior for HIV/AIDS was higher among ethnic minority migrant than ethnic Han migrant with a significant difference. After controlling demographic characteristics and migration model, ethnic Miao and Bouyei migrants were more likely to report the high risk sexual behavior for HIV/AIDS than ethnic Han migrant. This suggests that the relevant government departments should pay an attention on the high risk sexual behavior for HIV/AIDS among ethnic Miao and Bouyei migrants, and set them as a target group of intervention on the high risk sexual behavior for HIV/AIDS. In addition, the results show that male migrant was more likely to report the high risk sexual behavior for HIV/AIDS than female migrant. This finding was consistent with the result of other study [6]. The possible reasons are that migrants had the value of male as the center, and 
female migrant was in a lower social-economic status than male migrant. It suggests that eliminating gender inequality should be one of the strategies of intervention on the high risk sexual behavior for HIV/AIDS. Moreover, the results show that the migrants at the age of 35 or older were more likely to report the high risk sexual behavior for HIV/AIDS than the migrants at the age of 15 to 24 . The possible reasons are that migrants at the age of 15 to 24 were young with active sex. And most of them were unmarried and had not any fixed sexual partners. Thus, the intervention on the high risk sexual behavior for HIV/AIDS should be carried out among the migrants at the age of 15 to 24, e.g., peer education, life skills training, and healthy cultural and sports activities. Further, the results show that migrants crossing county or town were more likely to report the high risk sexual behavior for HIV/AIDS than migrants crossing province. In the field study, the authors were told that most of the migrants crossing province were senior management personnel or experts of the enterprise. They can enjoy their paid home vacation for one month every six month. The percentage of crossing province was lower among ethnic minority migrant than among ethnic Han migrant, and the percentage of crossing county was higher among ethnic minority migrant than among ethnic Han migrant. This suggests that the relevant agency should implement the intervention on the high risk sexual behavior for HIV/AIDS among ethnic minority migrants crossing county or town, and make a paid vacation policy for migrant workers, or allow their family members to visit them in the working site with payment. Finally, the results also show that the migrants with 3 floating cities (towns) in the last year were more likely to report the high risk sexual behavior for HIV/AIDS than the migrants with 1 floating city (town). This result was consistent with the other research finding [7]. According to social isolation theory and social control theory, the more migrants changed a city (town), the more migrants were away from the original social and moral control system, the more migrants lost the control of the high risk sexual behavior for HIV/AIDS from their family and society. Therefore, in order to increase the consciousness of protecting themselves and reduce the high risk sexual behavior for HIV/AIDS among migrants, the enterprise and government agency should strengthen the management of migrants, take the measures to stabilize migrants, and reduce the flow frequency of migrant in different cities (towns) [8].

\section{Acknowledgement}

This study was financially supported by the Social Science and Humanity Planning Project, Ministry of Education of the People's Republic of China (No. 11YJAZH034), and the National Social Science Fund Project of China (14BGL213).

\section{References}

[1] L. Wang, M.L. Bao, S.C. Song, et al, Evaluation on the effect of behavior intervention for AIDS prevention among migrant workers in Guiyang. Modern Preventive Medicine. 2012, 39(6) 1528-1531.

[2] N. Zhang, M. Wu, Chinese minority related AIDS problem study and think. Guizhou Ethnic Studies. 2011, 32(4) 37-43.

[3] Research group of current situation and countermeasure for AIDS prevention in ethnic minority areas, Report of the current situation and countermeasure for AIDS prevention in ethnic minority areas, in: H.Y. Zhang, Y.G. Hou, E. Ding (Eds), Development costs: research anthology on drugs hurt in ethnic minority areas in West China and HIV/AIDS problem, Publishing House of Central University for Nationalities, Beijing, 2009, pp.3-38.

[4] A.M. Wang, S.G. Lei, Z.M. Liu, et al, An investigation into HIV infection among drug users in Zhijin county in Guizhou province. Modern Preventive Medicine. 2006, 33(3) 364-365.

[5] China Center for Disease Control and Prevention, Center for Sexual Transmitted Disease and HIV/AIDS Control and Prevention, The National Operation Manual of HIV/AIDS Sentinel Surveillance Program (2011), China Center for Disease Control and Prevention, Beijing, 2011. 
[6] Division of Policy Research and Information, National Center for AIDS, China Center for Disease Control and Prevention, Gender analysis of data on HIV epidemic and response in six provinces, Division of Policy Research and Information, National Center for AIDS, Center for Disease Control and Prevention, China, Beijing, 2010.

[7] X.Y. Lin, X.Y. Fang, D.H. Lin, et al, The relationship between the mobility model and high risk behaviors in rural to-urban migrants. Psychological Science. 2006, 29(5) 1206-1210.

[8] E.Q. Zeng, X.B. Tian, J.L. Feng, et al, When AIDS confronts transient population-----an analysis of polices and laws concerning management of transient population in China, Modern Preventive Medicine. 2012, 39(2) 345-346, 351. 